\title{
Antioxidant Properties of Brazilian Tropical Fruits by Correlation between Different Assays
}

\author{
Elena Gregoris, ${ }^{1}$ Giuseppina Pace Pereira Lima, ${ }^{2}$ Sabrina Fabris, ${ }^{1}$ Mariangela Bertelle, \\ Michela Sicari, ${ }^{1}$ and Roberto Stevanato ${ }^{1}$ \\ ${ }^{1}$ Department of Molecular Sciences and Nanosystems, University Ca' Foscari of Venice, Dorsoduro 2137, 30123 Venice, Italy \\ ${ }^{2}$ Institute of Biosciences, UNESP University, Campus of Botucatu, CP 510, 18618-000 Botucatu, SA, Brazil \\ Correspondence should be addressed to Roberto Stevanato; rstev@unive.it
}

Received 16 April 2013; Revised 16 July 2013; Accepted 23 July 2013

Academic Editor: Filippo De Simone

Copyright (C) 2013 Elena Gregoris et al. This is an open access article distributed under the Creative Commons Attribution License, which permits unrestricted use, distribution, and reproduction in any medium, provided the original work is properly cited.

\begin{abstract}
Four different assays (the Folin-Ciocalteu, DPPH, enzymatic method, and inhibitory activity on lipid peroxidation) based on radically different physicochemical principles and normally used to determine the antioxidant activity of food have been confronted and utilized to investigate the antioxidant activity of fruits originated from Brazil, with particular attention to more exotic and less-studied species (jurubeba, Solanum paniculatum; pequi, Caryocar brasiliense; pitaya, Hylocereus undatus; siriguela, Spondias purpurea; umbu, Spondias tuberosa) in order to (i) verify the correlations between results obtained by the different assays, with the final purpose to obtain more reliable results avoiding possible measuring-method linked mistakes and (ii) individuate the more active fruit species. As expected, the different methods give different responses, depending on the specific assay reaction. Anyhow all results indicate high antioxidant properties for siriguela and jurubeba and poor values for pitaya, umbu, and pequi. Considering that no marked difference of ascorbic acid content has been detected among the different fruits, experimental data suggest that antioxidant activities of the investigated Brazilian fruits are poorly correlated with this molecule, principally depending on their total polyphenolic content.
\end{abstract}

\section{Introduction}

It is known that the consumption of fruit and vegetable reduces the incidence of cardiovascular and cerebrovascular diseases, stroke, cancer, and ageing related disorders [1-3]. This effect is attributed to the presence in fruit and vegetables of antioxidants able to preserve the correct balance oxidants/antioxidants, in which upset due to an overproduction of oxygen reactive species (ROS) can lead to the so-called "oxidative stress" [4-6].

Substantial damages have been observed when ROS interact with DNA, membrane lipids, and proteins [7-10]. ROS are involved in the carcinogenic stages of initiation, promotion, and progression [11]; they play an important role in the development of cardiovascular diseases such as ischemic injury, arteriosclerosis, hypertension, cardiomyopathies, congenital heart diseases, and stroke; they may be a causal factor of neurological disorders such as Alzheimer's and Parkinson's diseases [12].
Antioxidant substances represent one of the most important defense mechanisms against free radicals, but the only endogenous antioxidant molecules cannot be effective enough to counteract the injuries caused by ROS, particularly in the current times, where lifestyles based on smoke, drugs, alcohol, unbalanced diet, pollution, incorrect exposure to solar radiation, and so forth can facilitate free radicals formation. For this reason increasing the intake of dietary antioxidant is of great importance to enjoy good health, as evidenced by studies on food characterized by high antioxidants content [13].

Unfortunately, no reliable biomarker of antioxidant activity is available up to now $[14,15]$ because ROS injuries are mediated by different radical and nonradical species which show different physicochemical characteristics and reaction mechanism affecting reactivity, selectivity, partition in aqueous and lipid phase, and so forth [16]. In literature many experimental methods are reported to determine a generic 
antioxidant activity of a compound, but results obtained by different investigations are frequently contradictory [17].

The aim of this work is to compare of the results obtained by four different methods usually employed to measure antioxidant properties, that is, reducing capacity by the FolinCiocalteu assay, radical scavenging ability towards $2,2^{\prime}$ diphenyl-1-picrylhydrazyl (DPPH method), inhibitory ability on peroxidation of linoleic acid (LA), and total phenolic determination by the enzymatic method [18] in order to (i) verify possible correlations between the results obtained and (ii) obtain more reliable results avoiding possible measuringmethod linked mistakes.

These assays were applied to a series of Brazil fruits, with particular interest in the more exotic and less studied species. In fact, information on the nutritional values of the most exotic species of tropical fruits are limited: some studies [1922] provide evidence for the high antioxidant capacity and significant amounts of flavonoids and vitamin $\mathrm{C}$ for the most common Brazilian fruits as mango [23], starfruit [19], and avocado [24], but no data are reported for more exotic fruits, like pitaya, jurubeba, siriguela, and pequi, some of which native peoples utilize in popular medicine.

The results obtained by these measurements were compared with each other and with those obtained by Italian soft fruits known for their antioxidant activity [25, 26]. Furthermore, to discriminate possible interferences due to ascorbic acid and anthocyanins, the content of these reducing molecules in all fruits was also carried out.

Similitude and differences were discussed on the light of the chemical characteristics of the assay reactions.

\section{Materials and Methods}

2.1. Chemicals. All chemicals, of the highest available quality, were obtained from Sigma Chemical Co. (St. Louis, USA); ABIP (2,2' -azobis[2' -(2-imidazolin-2-yl)propane] dihydrochloride) was obtained from Wako Chemicals (Germany). The aqueous solutions were prepared with quality milli-Q water. Each experiment was in triplicate.

2.2. UV-VIS and Electrochemical Measurements. Spectrophotometric measurements were recorded on a UV-VIS Shimadzu UV-1800 instrument equipped with a temperature controlled quartz cell. The measures of oxygen consumption were performed with a potentiostat Amel 559, equipped with an oxygen microelectrode (MI-730, Microelectrodes).

2.3. Fruits and Sample Pretreatments. Table 1 reports common and scientific names of all studied fruits. Mango, avocado, carambola, and pitaya were from Sao Paulo state, while jurubeba, umbu, graviola, pequi, siriguela, and tamarind were from tropical Brazil; soft fruits were from Italy. After cleaning with distilled water, edible fruits portions were grated and centrifuged by a Krups centrifuge under nitrogen flux to avoid the oxidation of the natural components, and the juice was immediately analysed.

2.4. Inhibition of Lipid Peroxidation (ILP). The antioxidant activity of fruits to prevent linoleic acid (LA) peroxidation
TABLE 1: Selected fruits and their abbreviation.

\begin{tabular}{lcc}
\hline Scientific name & Common name & Abbreviation \\
\hline Persea americana & Avocado & $\mathrm{Av}$ \\
Annona muricata & Graviola & $\mathrm{Gr}$ \\
Solanum paniculatum & Jurubeba & $\mathrm{Ju}$ \\
Mangifera indica & Mango Haden & $\mathrm{MH}$ \\
Mangifera indica & Mango Palmer & $\mathrm{MP}$ \\
Mangifera indica & Mango Tommy Atkins & $\mathrm{MT}$ \\
Caryocar brasiliense & Pequi & $\mathrm{Pe}$ \\
Hylocereus undatus & Pitaya & $\mathrm{Pi}$ \\
Spondias purpurea & Purple mombin (siriguela) & $\mathrm{Si}$ \\
Averrhoa carambola & Starfruit (carambola) & $\mathrm{St}$ \\
Tamarindus indica & Tamarind & $\mathrm{Ta}$ \\
Spondias tuberosa & Umbu & $\mathrm{Um}$ \\
Rubus ulmifolius & Blackberry & $\mathrm{Ba}$ \\
Vaccinium cyanococcus & Blueberry & $\mathrm{Bu}$ \\
Rubus idceus & Raspberry & $\mathrm{Ra}$ \\
Ribes rubrum & Redcurrant & $\mathrm{Re}$ \\
Fragaria & Strawberry & $\mathrm{Sw}$ \\
\hline
\end{tabular}

was determined in sodium dodecyl sulfate (SDS) micelles. As previously reported [27], the fruit's antioxidant capacity was calculated as the juice concentration ( $\mathrm{ppm}$ ) halves the rate of oxygen consumption due to the peroxidation process, and it is expressed as inhibitory concentration $\mathrm{IC}_{50}$.

\subsection{2,2-Diphenyl-1-picrylhydrazyl (DPPH) Radical Scavenging Capacity Assay. This method is based on the capacity of an antioxidant to scavenge the stable free radical DPPH [28]. The procedure is reported in Stevanato et al. [18]; the results are expressed as catechin equivalent concentration (CE).}

2.6. Folin-Ciocalteu Assay and Total Phenolics Content (TPC) by Enzymatic Method. The Folin-Ciocalteu assay and the Total Phenolic Content were determined spectrophotometrically, according to the procedures previously reported [18], and the results were expressed as catechin equivalent (CE).

2.7. Total Hydroxycinnamic Acid Content (HCA). Hydroxycinnamic acid content was determined according to Zaporozhets et al. [29]. The complex of hydroxycinnamic acids with aluminium (III) was measured at $365 \mathrm{~nm}$, and caffeic acid was used as a standard; the results were expressed as milligrams/liter of caffeic acid equivalents.

2.8. Total Anthocyanin Content (TAC). The TAC was determined according the $\mathrm{pH}$-differential method [30]. Absorbance at 510 and $700 \mathrm{~nm}$ of juice buffered at pH 4.5 e 1.0 was calculated. The anthocyanin concentration was expressed as milligrams/liter of cyanidin-3-glucoside equivalents. 
TABLE 2: Results obtained by ILP, DPPH, TPC, Folin, HCA, and TAA assays of selected fruits.

\begin{tabular}{|c|c|c|c|c|c|c|c|}
\hline Fruit & Abbreviation & $\begin{array}{c}\text { ILP } \\
\text { IC }_{50}(\mathrm{ppm}) \\
\end{array}$ & $\begin{array}{c}\mathrm{DPPH} \\
\mathrm{CE}(\mathrm{mM})\end{array}$ & $\begin{array}{c}\text { TPC } \\
\mathrm{CE}(\mathrm{mM}) \\
\end{array}$ & $\begin{array}{c}\text { Folin } \\
\mathrm{CE}(\mathrm{mM})\end{array}$ & $\begin{array}{c}\text { HCA } \\
(\mathrm{mg} / \mathrm{L})\end{array}$ & $\begin{array}{l}\text { TAA } \\
(\mathrm{mM})\end{array}$ \\
\hline Avocado & $\mathrm{Av}$ & $240 \pm 20$ & $0.1 \pm 0.01$ & $1.06 \pm 0.05$ & $1.99 \pm 0.04$ & $56 \pm 6$ & $3.1 \pm 0.2$ \\
\hline Graviola & Gr & $87 \pm 9$ & $2.4 \pm 0.6$ & $3.7 \pm 0.5$ & $8.6 \pm 0.4$ & $42 \pm 3$ & $4.7 \pm 0.2$ \\
\hline Jurubeba & $\mathrm{Ju}$ & $60 \pm 8$ & $0.9 \pm 0.3$ & $7.8 \pm 0.5$ & $36 \pm 2$ & $3242 \pm 20$ & $3.4 \pm 0.2$ \\
\hline Mango Haden & $\mathrm{MH}$ & $200 \pm 20$ & $0.31 \pm 0.05$ & $0.75 \pm 0.09$ & $5.7 \pm 0.2$ & $184 \pm 12$ & $8.6 \pm 0.8$ \\
\hline Mango Palmer & MP & $240 \pm 20$ & $0.89 \pm 0.01$ & $1.21 \pm 0.05$ & $4.5 \pm 0.3$ & $80 \pm 9$ & $5 \pm 1$ \\
\hline Mango Tommy Atkins & MT & $300 \pm 20$ & $0.50 \pm 0.07$ & $0.15 \pm 0.03$ & $1.4 \pm 0.1$ & $90 \pm 10$ & $3.7 \pm 0.6$ \\
\hline Pequi & $\mathrm{Pe}$ & $500 \pm 50$ & $0.1 \pm 0.01$ & $0.5 \pm 0.1$ & $7.9 \pm 0.2$ & $66 \pm 7$ & $2.4 \pm 0.3$ \\
\hline Pitaya & $\mathrm{Pi}$ & $1000 \pm 100$ & $0.1 \pm 0.01$ & $1.6 \pm 0.2$ & $2.1 \pm 0.2$ & $152 \pm 12$ & $2.6 \pm 0.2$ \\
\hline Siriguela & $\mathrm{Si}$ & $44 \pm 4$ & $8 \pm 1$ & $3.2 \pm 0.1$ & $34 \pm 5$ & $264 \pm 23$ & $4.7 \pm 0.3$ \\
\hline Carambola & St & $70 \pm 7$ & $2.5 \pm 0.1$ & $5.4 \pm 0.4$ & $10.5 \pm 0.1$ & $164 \pm 14$ & $4.2 \pm 0.3$ \\
\hline Tamarind & $\mathrm{Ta}$ & $100 \pm 20$ & $2.4 \pm 0.3$ & $2.9 \pm 0.1$ & $18.5 \pm 0.8$ & $168 \pm 15$ & $7 \pm 1$ \\
\hline Umbu & Um & $500 \pm 30$ & $0.67 \pm 0.05$ & $1.4 \pm 0.2$ & $4.2 \pm 0.1$ & 46. \pm 3 & $1.5 \pm 0.2$ \\
\hline Blackberry & $\mathrm{Ba}$ & $109 \pm 6$ & $3.0 \pm 0.2$ & $2.66 \pm 0.06$ & $8.4 \pm 0.1$ & $203 \pm 19$ & $4.4 \pm 0.6$ \\
\hline Blueberry & $\mathrm{Bu}$ & $41 \pm 7$ & $3.4 \pm 0.1$ & $2.8 \pm 0.1$ & $7.8 \pm 0.5$ & $350 \pm 25$ & $3.0 \pm 0.1$ \\
\hline Raspberry & $\mathrm{Ra}$ & $77 \pm 9$ & $4.2 \pm 0.1$ & $2.7 \pm 0.1$ & $21 \pm 1$ & $101 \pm 9$ & $3.7 \pm 0.3$ \\
\hline Redcurrant & $\mathrm{Re}$ & $56 \pm 2$ & $3.4 \pm 0.4$ & $3.9 \pm 0.4$ & $10.0 \pm 0.1$ & $180 \pm 12$ & $4 \pm 0.4$ \\
\hline Strawberry & Sw & $38 \pm 4$ & $4.1 \pm 0.3$ & $3.04 \pm 0.09$ & $10 \pm 3$ & $190 \pm 13$ & $6 \pm 1$ \\
\hline
\end{tabular}

2.9. Total Ascorbic Acid (TAA). The TAA is assayed as previously described [31] with minor modifications. A $20 \mathrm{mM}$ oxalic acid solution containing the sample, $0.186 \mathrm{mM} \mathrm{2,6-}$ dichlorophenol-indophenol (DCFI), $10 \mathrm{mM}$ dinitrophenylhydrazine (DNPH), and $13 \mathrm{mM}$ thiourea were incubated in a boiling water bath for 15 minutes. Once cooled, an equal volume of $85 \%$ sulfuric acid was added to the solution, and the absorbance at $520 \mathrm{~nm}$ was measured 15 minutes later. The same procedure was repeated without the sample, and the blank value was subtracted from the absorbance of the sample.

In Table 2, where the results obtained by applying ILP, Folin, DPPH, and TPC enzymatic methods are reported, it appears that jurubeba and siriguela show very low $\mathrm{IC}_{50}$ values (i.e., high antioxidant activity) in the range of those found for the more active Italian soft fruits (blueberry, redcurrant, and raspberry). For the same fruits, DPPH, TPC, and Folin assays give very high values of $\mathrm{CE}$, if compared with the average of other fruits, indicating an univocal high antioxidant activity of these two fruits.

On the basis of their $\mathrm{IC}_{50}$ values, the investigated Brazilian tropical fruits can be roughly divided into three groups characterized approximately by good, medium, and poor antioxidant properties, respectively (Figure 1): (1) fruits with $\log \left(\mathrm{IC}_{50}\right) \leq 2\left(\mathrm{IC}_{50} \leq 100 \mathrm{ppm}\right)$ : graviola, jurubeba, siriguela, carambola, and tamarind; (2) fruits with $2<\log \left(\mathrm{IC}_{50}\right) \leq 2.5$ ( $\mathrm{IC}_{50}$ ranging from 100 to $316 \mathrm{ppm}$ ): avocado and mango; (3) fruits with $\log \left(\mathrm{IC}_{50}\right)>2.5\left(\mathrm{IC}_{50}>316 \mathrm{ppm}\right)$ : pequi, umbu, and pitaya.

In Figure 2, correlations between data obtained by ILP expressed as $1 / \mathrm{IC}_{50}$ and other adopted methods expressed as catechin equivalent amount (CE) are reported.
The comparison of the data obtained by ILP versus DPPH scavenging methods (Figure $2(\mathrm{a})$ ) points out a good correlation $(R=0.79)$; in fact only few points referred to that strawberry, blueberry, jurubeba, and, in less amount, siriguela scatter from the linear relationship.

Analogous graph created for comparison of ILP with enzymatic or the Folin methods (Figures 2(b) and 2(c)) shows less good correlations ( $R=0.60$ and 0.30 , resp.), but also in this case strawberry, blueberry, jurubeba, and, in part, siriguela appear to worsen the correlation coefficient.

TAC measurements showed the absence of anthocyanins in analyzed Brazilian fruits, while as regards the hydroxycinnamic acid content, the values of HCA equivalents obtained for the studied fruits and reported in Table 2 show a very high value of $\mathrm{HCA}_{\mathrm{eq}}$ for jurubeba.

No correlation appears comparing TAA values with the data obtained by the other analytical methods (data are not showed).

\section{Discussion}

3.1. On the Assay Methods. Several methods are proposed to evaluate the antioxidant activity of molecules or food [26$28,32-35]$. Each assay measures a specific chemical or physicochemical parameter which can be correlated with the complex and in part unknown mechanisms related to ROS injury. It follows that the results obtained are partial and sometime are affected by other variables not strictly correlated to the antioxidant activity. In this work, we chose four different assays which significantly represent the main methods of measuring the antioxidant properties of a substance.

The Folin-Ciocalteu is a very aged and largely used assay, based on the absorbance changes due to the oxidation of any 


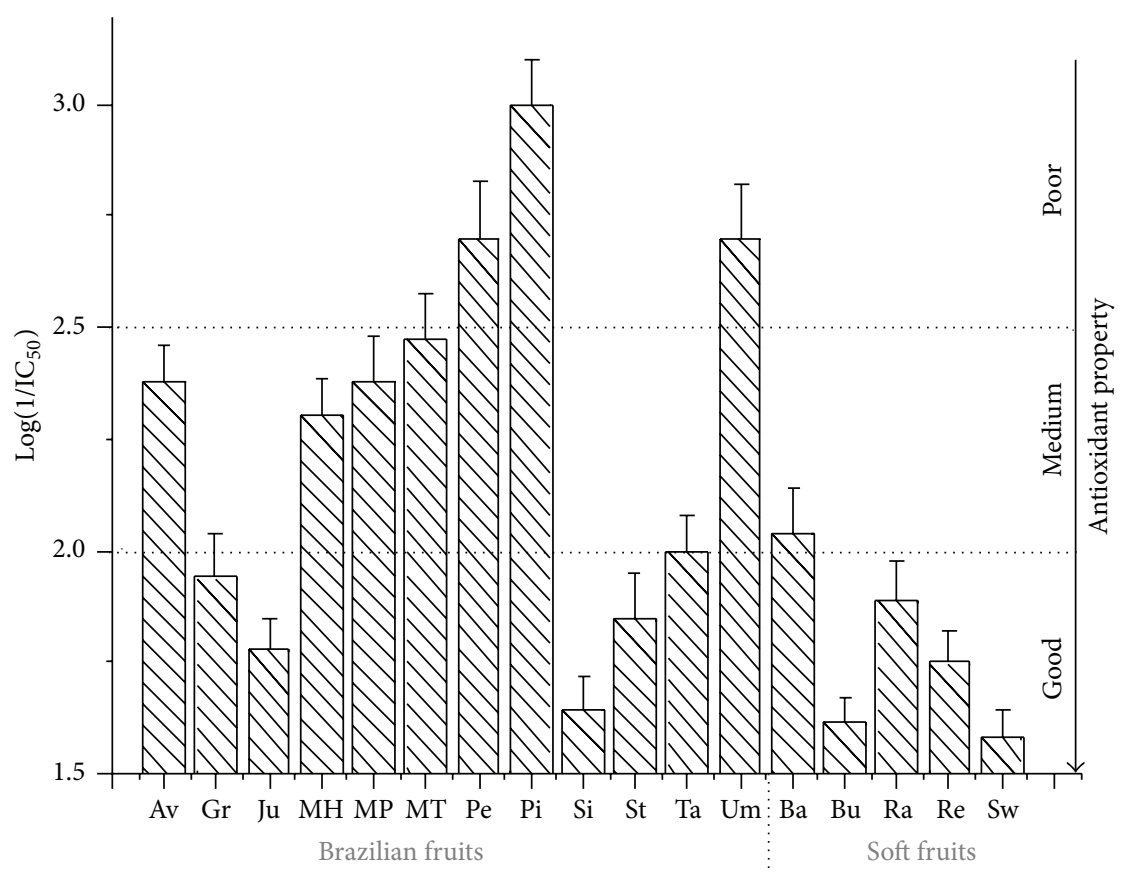

FIGURE 1: Classification of studied fruits on the base of their logarithm $\mathrm{IC}_{50}$ values.

reduced compounds by a phosphomolybdate and phosphotungstate solution. It is a nonspecific method of measuring the reducing capacity of all the components of the sample other than polyphenols, such as ascorbate $[18,36]$. In fact, to avoid an overestimated evaluation of the antioxidant capacity, laborious pretreatments of the sample are suggested [37].

TPC enzymatic method, on the contrary, being a measure of the total phenolic content of fruit due to the specificity of peroxidase-catalyzed reaction towards phenolic structures, is an indirect evaluation of the antioxidant power, which actually depends not only on the measured total phenolic content, but also on the chemical structure of each phenolic component [14].

DPPH method is a measure of the electronic transfer from the phenolic structure to the stable free radical DPPH, but this reaction presents the following disadvantages which can underestimate the antioxidant capacity:

(i) it may react slowly or be inert to many antioxidants [38];

(ii) reaction kinetic with antioxidants appears not linear to DPPH concentrations [36];

(iii) reaction of DPPH with some phenolic structures could not go to completion, reaching an equilibrium state, as found for eugenol [36].

\section{Results}

By a physicochemical point of view, ILP technique appears to better reproduce the in vivo action of antioxidant substances against radical-induced lipid peroxidation of unsaturated fatty acids residues of biological membranes, measuring in vitro the slowdown, due to an antioxidant, of the oxygen consumption in linoleic acid containing SDS micelles. In this case, the influence due to the different lipophilicity of the antioxidant molecules is taken in account too. Moreover, in this work, only clear juices have been analyzed, and, as a consequence, only water soluble antioxidants have been assessed.

Anyway, in order to be certain of the data reliability and to give a wider outlook of the problems related to the definition of the antioxidant activity of foods, the same samples were studied by the above cited four analytical assays, and the results were compared to put in light possible correlations. In fact, good correlations between results obtained by different assays can guarantee the best evaluation of the antioxidant properties of a sample.

4.1. On the Antioxidant Characteristics of Brazilian Fruits. Siriguela, jurubeba, carambola, graviola, and tamarind show high antioxidant activity, similar to that of soft fruits $[25,26]$. This result appears very important considering that for some of these fruits no information in literature is reported, in particular about their antioxidant properties [39]. Moreover, the widespread use for curative actions into local populations of some of these fruits, in particular jurubeba and siriguela, suggests further investigations for their possible nutraceutical properties.

With reference to the scattering from the linear correlation of the data referred to strawberry, blueberry, jurubeba, and siriguela, as it results in all three graphs of Figure 2, plots of correlation of the data obtained by DPPH, Folin, and enzymatic methods are graphed in order to verify if this deviation could be due to a limit of the ILP assay (Figure 3). 


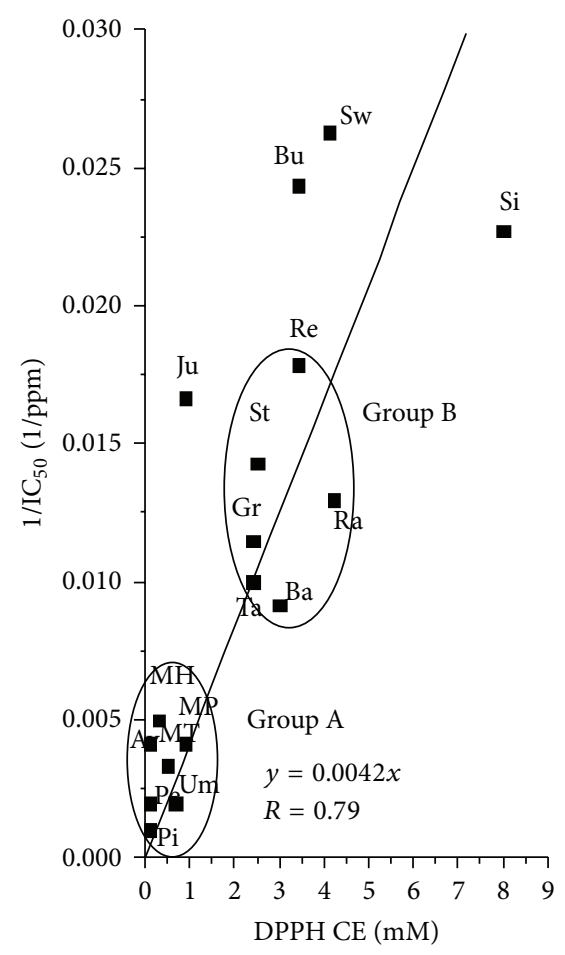

(a)

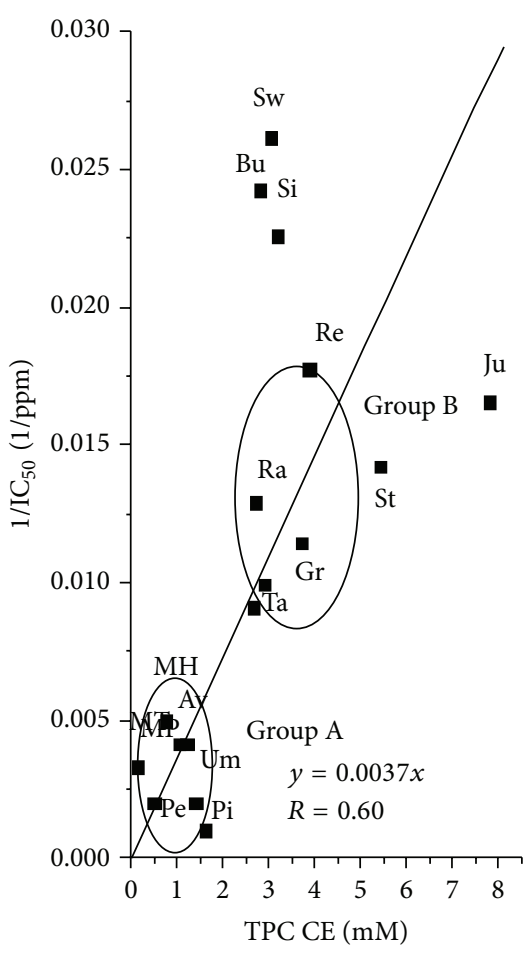

(b)

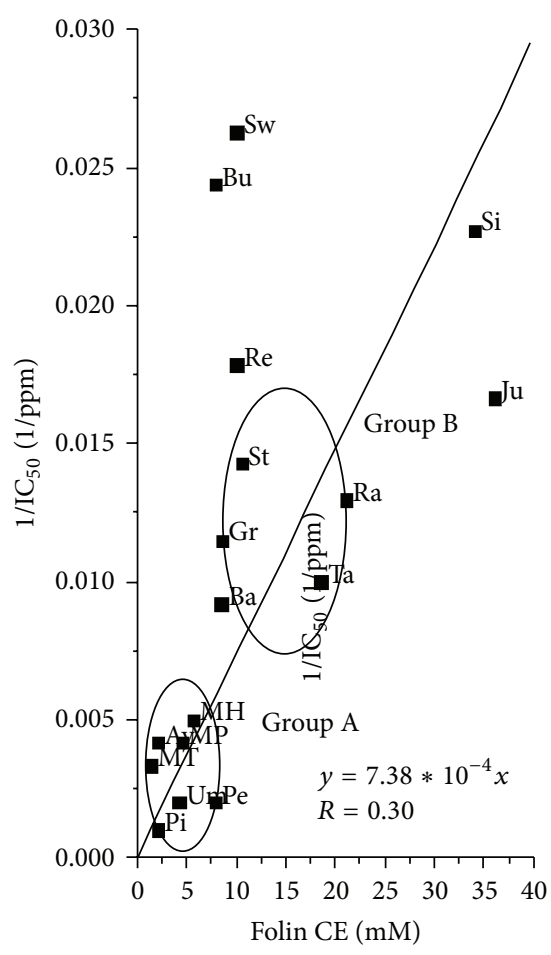

(c)

FIgURE 2: Correlation between ILP and (a) DPPH, (b) enzymatic, and (c) Folin assay.

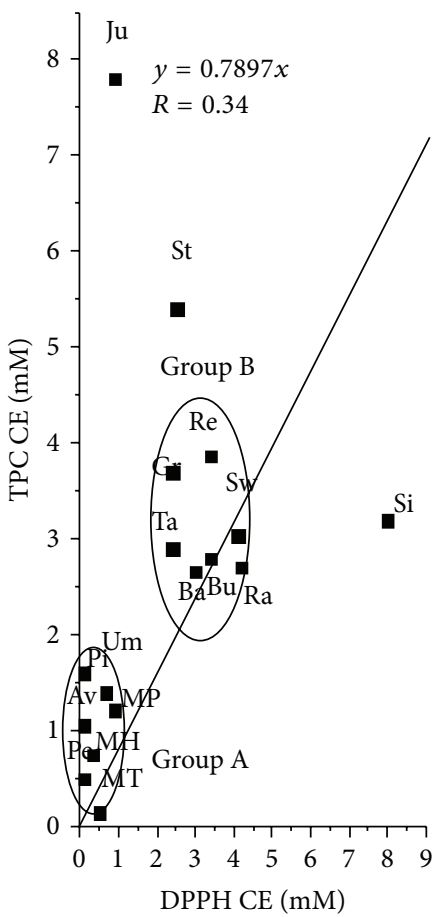

(a)

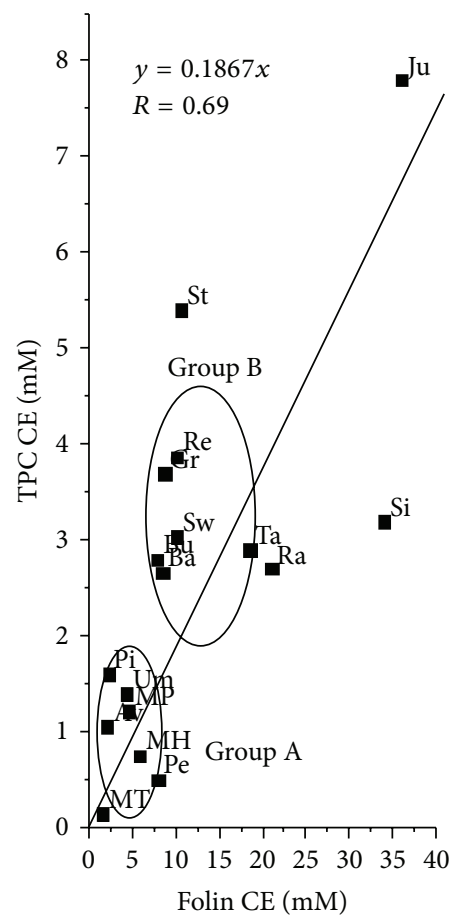

(b)

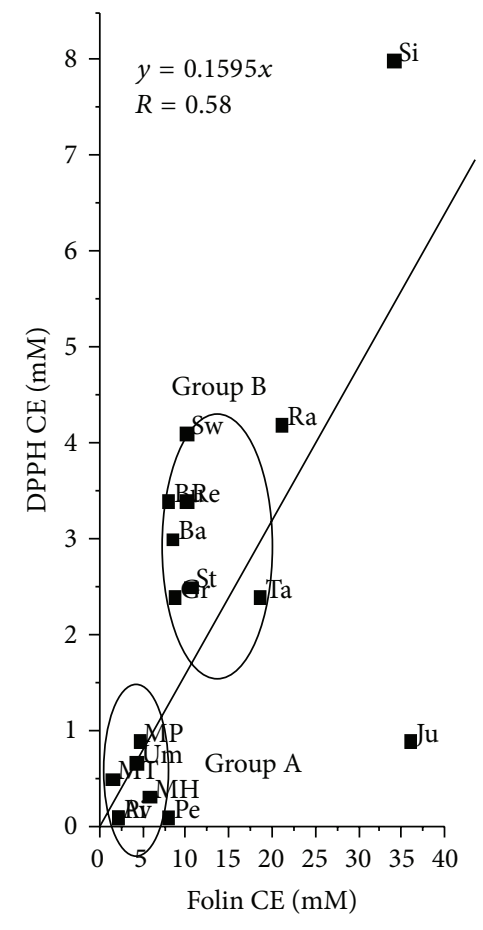

(c)

FIgURE 3: Correlation between (a) enzymatic and DPPH; (b) enzymatic and Folin; (c) DPPH and Folin assays. 


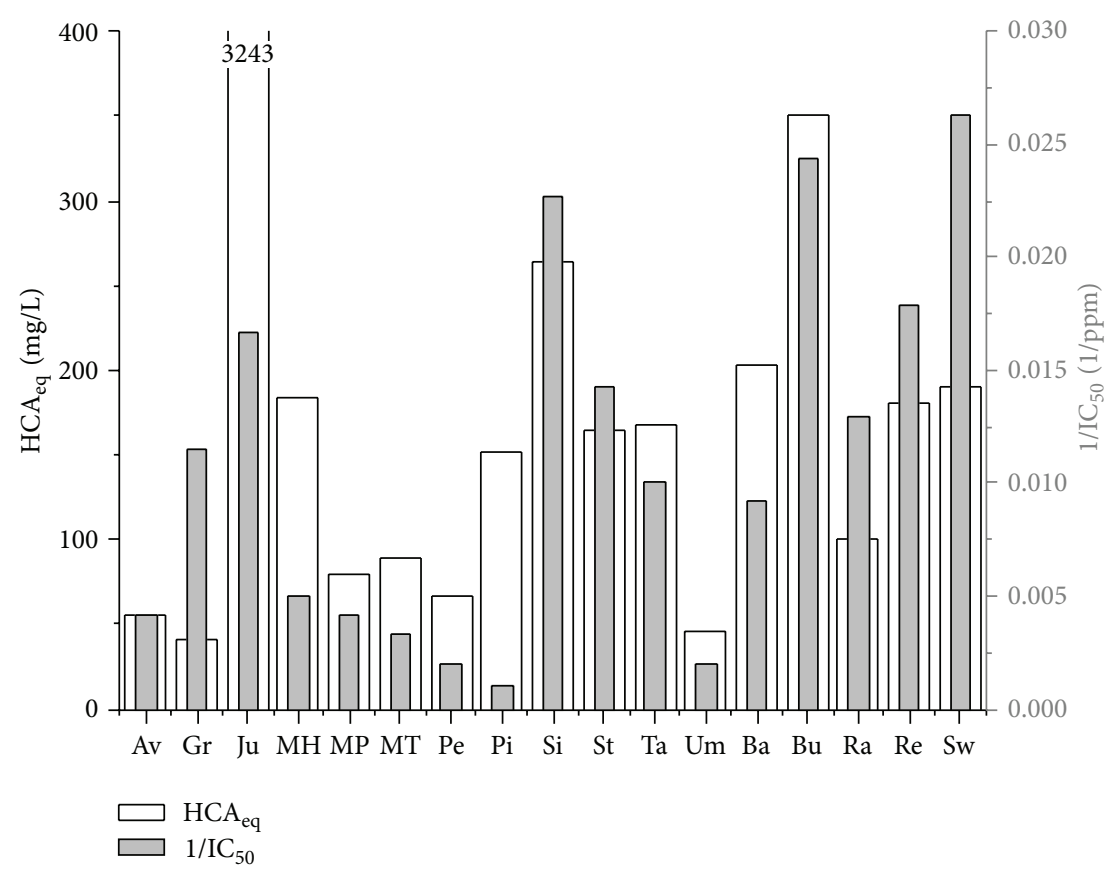

FIgURE 4: Correlation between ILP and HCA equivalents.

Also in these cases, the data of the above-mentioned fruits appear considerably out of the correlation straight line, indicating that the chemical compounds that are responsible of the antioxidant activity are differently recorded by the different analytical methods.

Jurubeba and siriguela are two striking examples of how different assays may assign different rankings to antioxidant molecules: as it appears in Figure 3(a), while the antioxidant activity of jurubeba is high when evaluated by the enzymatic method and low when evaluated by DPPH, in the case of siriguela the DPPH method assigns it excellent antioxidant properties which are not confirmed by the enzymatic assay. The result of the first case can be due to the high content in jurubeba of polyphenols characterized by a low tendency to undergo monoelectronic transfer to $\mathrm{DPPH}$, as recently verified for different flavonoids [14]. Further investigations to clarify this contrasting behaviour are necessary in any case.

The better correlation results from the comparison of the ILP and DPPH data (Figure 2(a)). In fact, both the analytical methods are based on the redox potentials of the monoelectronic transfer, and they appear in some way as a direct measure of the radicals stopping power [28, 39] of the antioxidant substances in the fruit. Moreover, the joint data obtained by $\mathrm{IC}_{50}$ and DPPH experiments are particularly efficient for separating poor antioxidants from good ones: $\mathrm{IC}_{50}$ values that are lower than $100 \mathrm{ppm}$ and/or CE values that are higher than $2 \mathrm{mM}$ could be assumed as a reasonable rule for discriminating very good antioxidants.

Even if there is a bad correlation between DPPH and enzymatic data (Figure 3(a)), most of the fruit can be roughly separated in two groups (A and B) with different degrees of antioxidant activity, suggesting the hypothesis that fruit of the same group could have quite similar compositions of antioxidant constituents or molecules which react in similar way to the analytical methods.

Anthocyanins are not contained in examined Brazilian fruits, while hydroxycinnamic acids are detected; their correlation with ILP is practically absent, as shown in Figure 4. For this reason, antioxidant property must depend on other parameters.

Table 2 indicates that, in general, Brazilian fruits have ascorbic acid content comparable to that of soft fruits: among them two varieties of mango and tamarind have meaningfully high TAA content, and umbu have the lowest one.

No evident relationship between the antioxidant activity of fruit and the content of ascorbic acid is observed: siriguela and jurubeba have the highest antioxidant activity, but they exhibit lower values of vitamin $\mathrm{C}$ than mango, which is not a good antioxidant instead (Table 2). It follows that antioxidant activity of the majority of fruits is due to compounds different from vitamin C, like polyphenols, mainly flavonoids, according to results reported for other species of fruit $[11,22]$.

\section{Conclusion}

Brazilian fruits were used as arbitrary alimentary products to compare four different assays normally utilised to determine antioxidant activity of food.

The better correlation was found between the inhibition of lipid peroxidation and DPPH method. Both these assays are based on monoelectronic transfer, and, in our opinion, they mime, more than others, the efficacy of an antioxidant compound to prevent oxidative damage on cell membrane, despite all the limitations of the DPPH assay above reported 
and taking into account the laboriousness of the ILP method. From data obtained by these two methods, siriguela and jurubeba show the higher antioxidant activity.

The antioxidant activity of the majority of the studied fruit is due to compounds different from vitamin $\mathrm{C}$, like flavonoids, because no evident relationship between the antioxidant activity of fruit and the content of ascorbic acid was observed.

\section{Conflict of Interests}

This work is free from any conflict of interests.

\section{References}

[1] Willet and W. C. Eat, Drink, and Be Healthy: The Harvard Medical School Guide to Healthy Eating, McGraw-Hill, New York, NY, USA, 2001.

[2] Z. Juranic and K. Z. Ziza, "Biological activities of berries: from antioxidant capacity to anti-cancer effects," BioFactors, vol. 23, no. 4, pp. 207-211, 2005.

[3] S. Zafra-Stone, T. Yasmin, M. Bagchi, A. Chatterjee, J. A. Vinson, and D. Bagchi, "Berry anthocyanins as novel antioxidants in human health and disease prevention," Molecular Nutrition and Food Research, vol. 51, no. 6, pp. 675-683, 2007.

[4] A. R. Ness and J. W. Powles, "Fruit and vegetables, and cardiovascular disease: a review," International Journal of Epidemiology, vol. 26, no. 1, pp. 1-13, 1997.

[5] H. Esterbauer, M. Dieber-Rotheneder, G. Striegl, and G. Waeg, "Role of vitamin $\mathrm{E}$ in preventing the oxidation of low-density lipoprotein," American Journal of Clinical Nutrition, vol. 53, pp. 314s-321s, 1991.

[6] M. A. Eastwood, "Interaction of dietary antioxidants in vivo: how fruit and vegetables prevent disease?" Quarterly Journal of Medicine, vol. 92, no. 9, pp. 527-530, 1999.

[7] L. J. Marnett, “Oxyradicals and DNA damage," Carcinogenesis, vol. 21, no. 3, pp. 361-370, 2000.

[8] B. Halliwell and J. M. C. Gutteridge, Free Radical Biology and Medicine, Oxford University Press, Oxford, UK, 3rd edition, 1999.

[9] H. Esterbauer and P. Ramos, "Chemistry and pathophysiology of oxidation of LDL," Reviews of Physiology Biochemistry and Pharmacology, vol. 127, pp. 31-64, 1996.

[10] H. Wang, G. Cao, and R. L. Prior, “Total antioxidant capacity of fruits," Journal of Agricultural and Food Chemistry, vol. 44, no. 3, pp. 701-705, 1996.

[11] M. Valko, C. J. Rhodes, J. Moncol, M. Izakovic, and M. Mazur, "Free radicals, metals and antioxidants in oxidative stressinduced cancer," Chemico-Biological Interactions, vol. 160, no. 1, pp. 1-40, 2006.

[12] M. Valko, D. Leibfritz, J. Moncol, M. T. D. Cronin, M. Mazur, and J. Telser, "Free radicals and antioxidants in normal physiological functions and human disease," International Journal of Biochemistry and Cell Biology, vol. 39, no. 1, pp. 44-84, 2007.

[13] M. Antolovich, P. D. Prenzler, E. Patsalides, S. McDonald, and K. Robards, "Methods for testing antioxidant activity," Analyst, vol. 127, no. 1, pp. 183-198, 2002.

[14] E. Gregoris and R. Stevanato, "Correlations between polyphenolic composition and antioxidant activity of Venetian propolis," Food and Chemical Toxicology, vol. 48, no. 1, pp. 76-82, 2009.
[15] G. Chiva-Blanch and F. Visioli, "Polyphenols and health: moving beyond antioxidants," Journal of Berry Research, vol. 2, pp. 63-71, 2012.

[16] M. Takashima, M. Horie, M. Shichiri, Y. Hagihara, Y. Yoshida, and E. Niki, "Assessment of antioxidant capacity for scavenging free radicals in vitro: a rational basis and practical application," Free Radical Biology and Medicine, vol. 52, no. 7, pp. 1242-1252, 2012.

[17] E. Niki, "Antioxidant capacity: which capacity and how to assess it?” Journal of Berry Research, vol. 1, pp. 169-176, 2011.

[18] R. Stevanato, S. Fabris, and F. Momo, "New enzymatic method for the determination of total phenolic content in tea and wine," Journal of Agricultural and Food Chemistry, vol. 52, no. 20, pp. 6287-6293, 2004.

[19] K. Mahattanatawee, J. A. Manthey, G. Luzio, S. T. Talcott, K. Goodner, and E. A. Baldwin, "Total antioxidant activity and fiber content of select Florida-grown tropical fruits," Journal of Agricultural and Food Chemistry, vol. 54, no. 19, pp. 7355-7363, 2006.

[20] S. A. de Assis, J. C. R. Vellosa, I. L. Brunetti et al., "Antioxidant activity, ascorbic acid and total phenol of exotic fruits occurring in Brazil," International Journal of Food Sciences and Nutrition, vol. 60, no. 5, pp. 439-448, 2009.

[21] N. M. A. Hassimotto, "Antioxidant capacity of Brazilian fruit, vegetables and commercially-frozen fruit pulps," Journal of Food Composition and Analysis, vol. 22, no. 5, pp. 394-396, 2009.

[22] M. I. Genovese, M. D. Pinto, A. E. D. Gonçalves, and F. M. Lajolo, "Bioactive compounds and antioxidant capacity of exotic fruits and commercial frozen pulps from Brazil," Food Science and Technology International, vol. 14, no. 3, pp. 207-241, 2008.

[23] J. A. Manthey and P. Perkins-Veazie, "Influences of harvest date and location on the levels of $\beta$-carotene, ascorbic acid, total phenols, the in vitro antioxidant capacity, and phenolic profiles of five commercial varieties of mango (Mangifera indica L.)," Journal of Agricultural and Food Chemistry, vol. 57, no. 22, pp. 10825-10830, 2009.

[24] L. Plaza, C. Sánchez-Moreno, S. de Pascual-Teresa, B. de Ancos, and M. P. Cano, "Fatty acids, sterols, and antioxidant activity in minimally processed avocados during refrigerated storage," Journal of Agricultural and Food Chemistry, vol. 57, no. 8, pp. 3204-3209, 2009.

[25] E. Sariburun, S. Şahin, C. Demir, C. Türkben, and V. Uylaşer, "Phenolic content and antioxidant activity of raspberry and blackberry cultivars," Journal of Food Science, vol. 75, no. 4, pp. C328-C335, 2010.

[26] S. Y. Wang and H. Lin, "Antioxidant activity in fruits and leaves of blackberry, raspberry, and strawberry varies with cultivar and developmental stage," Journal of Agricultural and Food Chemistry, vol. 48, no. 2, pp. 140-146, 2000.

[27] S. Fabris, F. Momo, G. Ravagnan, and R. Stevanato, "Antioxidant properties of resveratrol and piceid on lipid peroxidation in micelles and monolamellar liposomes," Biophysical Chemistry, vol. 135, no. 1-3, pp. 76-83, 2008.

[28] M. S. Blois, "Antioxidant determinations by the use of a stable free radical," Nature, vol. 181, no. 4617, pp. 1199-1200, 1958.

[29] O. A. Zaporozhets, E. A. Krushinsksya, V. N. Barvinchenko, N. A. Lipkovskaya, and V. K. Pogorelyi, "Spectrophotometric determination of hydroxycynnamic acid and related compounds in Echinacea preparations," Pharmaceutical Chemistry Journal, vol. 37, no. 12, pp. 632-636, 2003. 
[30] M. M. Giusti and R. E. Worsltad, "Characterization and measurement of anthocyanins by UV-visible spectroscopy," in Current Protocols in Food Analytical Chemistry, pp. F1. 2. 1-F1. 2. 13, John Wiley \& Sons, New York, NY, USA, 2001.

[31] J. H. Roe and C. A. Kuether, "The determination of ascobic acid in whole blood and urine through the 2, 4-dintrophenylhydrazine derivative of dehydroascorbic acid," The Journal of Biological Chemistry, vol. 147, pp. 399-407, 1943.

[32] R. Re, N. Pellegrini, A. Proteggente, A. Pannala, M. Yang, and C. Rice-Evans, "Antioxidant activity applying an improved ABTS radical cation decolorization assay," Free Radical Biology and Medicine, vol. 26, no. 9-10, pp. 1231-1237, 1999.

[33] W. A. Pryor, J. A. Cornicelli, L. J. Devall et al., "A rapid screening test to determine the antioxidant potencies of natural and synthetic antioxidants," Journal of Organic Chemistry, vol. 58, no. 13, pp. 3521-3532, 1993.

[34] G. Cao, H. M. Alessio, and R. G. Cutler, "Oxygen-radical absorbance capacity assay for antioxidants," Free Radical Biology and Medicine, vol. 14, no. 3, pp. 303-311, 1993.

[35] R. Stevanato, S. Fabris, M. Bertelle, E. Gregoris, and F. Momo, "Phenolic content and antioxidant properties of fermenting musts and fruit and vegetable fresh juices," Acta Alimentaria, vol. 38, no. 2, pp. 193-203, 2009.

[36] D. Huang, O. U. Boxin, and R. L. Prior, "The chemistry behind antioxidant capacity assays," Journal of Agricultural and Food Chemistry, vol. 53, no. 6, pp. 1841-1856, 2005.

[37] V. L. Singleton, R. Orthofer, and R. M. Lamuela-Raventós, "Analysis of total phenols and other oxidation substrates and antioxidants by means of folin-ciocalteu reagent," Methods in Enzymology, vol. 299, pp. 152-178, 1999.

[38] F. Nanjo, K. Goto, R. Seto, M. Suzuki, M. Sakai, and Y. Hara, "Scavenging effects of tea catechins and their derivatives on 1,1- diphenyl-2-picrylhydrazyl radical," Free Radical Biology and Medicine, vol. 21, no. 6, pp. 895-902, 1996.

[39] H. Lorenzi, S. F. Sartori, L. B. Bacher, and M. T. C. de Lacerda, Frutas Brasileiras, Instituto Planetarium de Estudos da Flora LTDA, Sao Paulo, Brazil, 2006. 

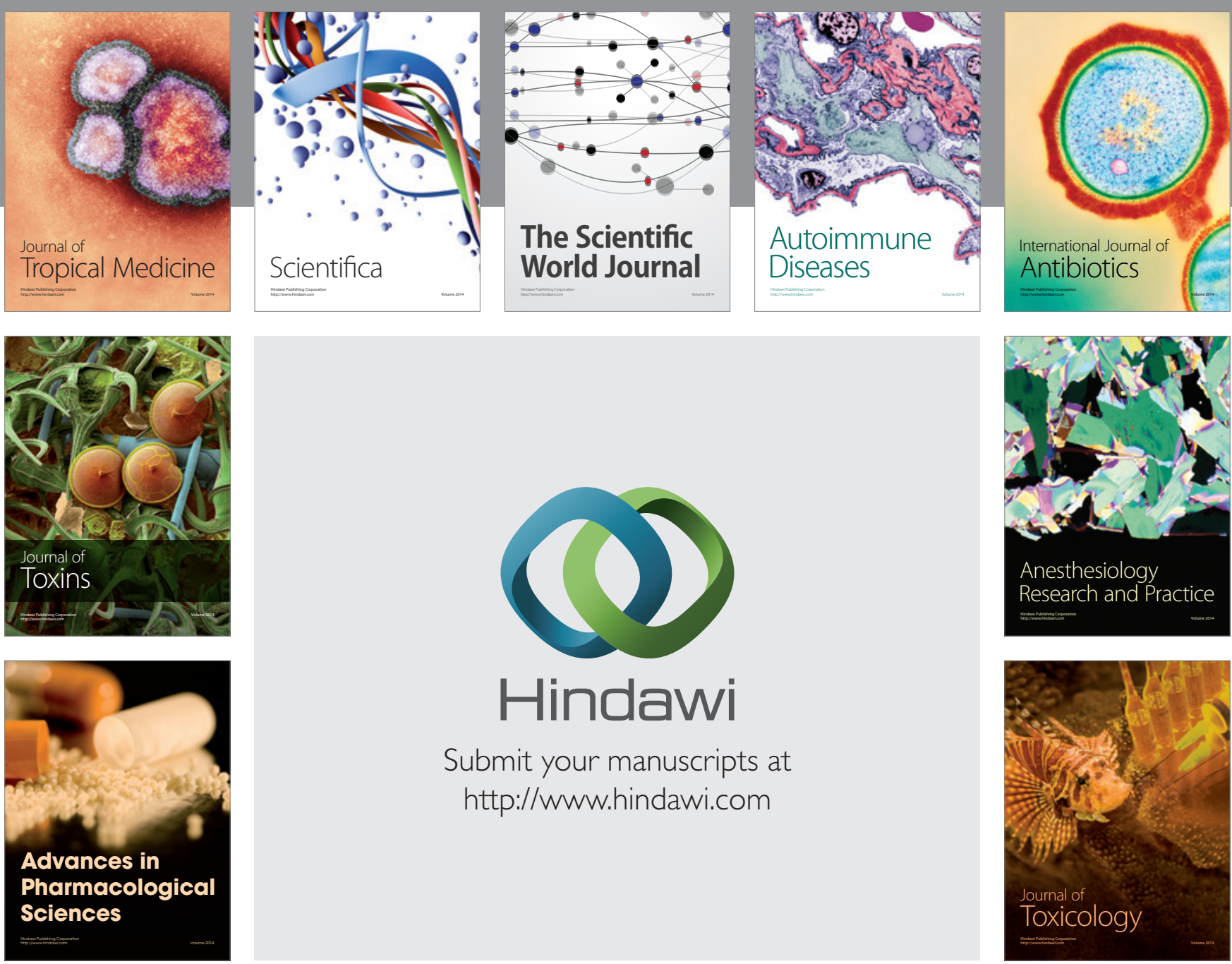

\section{Hindawi}

Submit your manuscripts at

http://www.hindawi.com
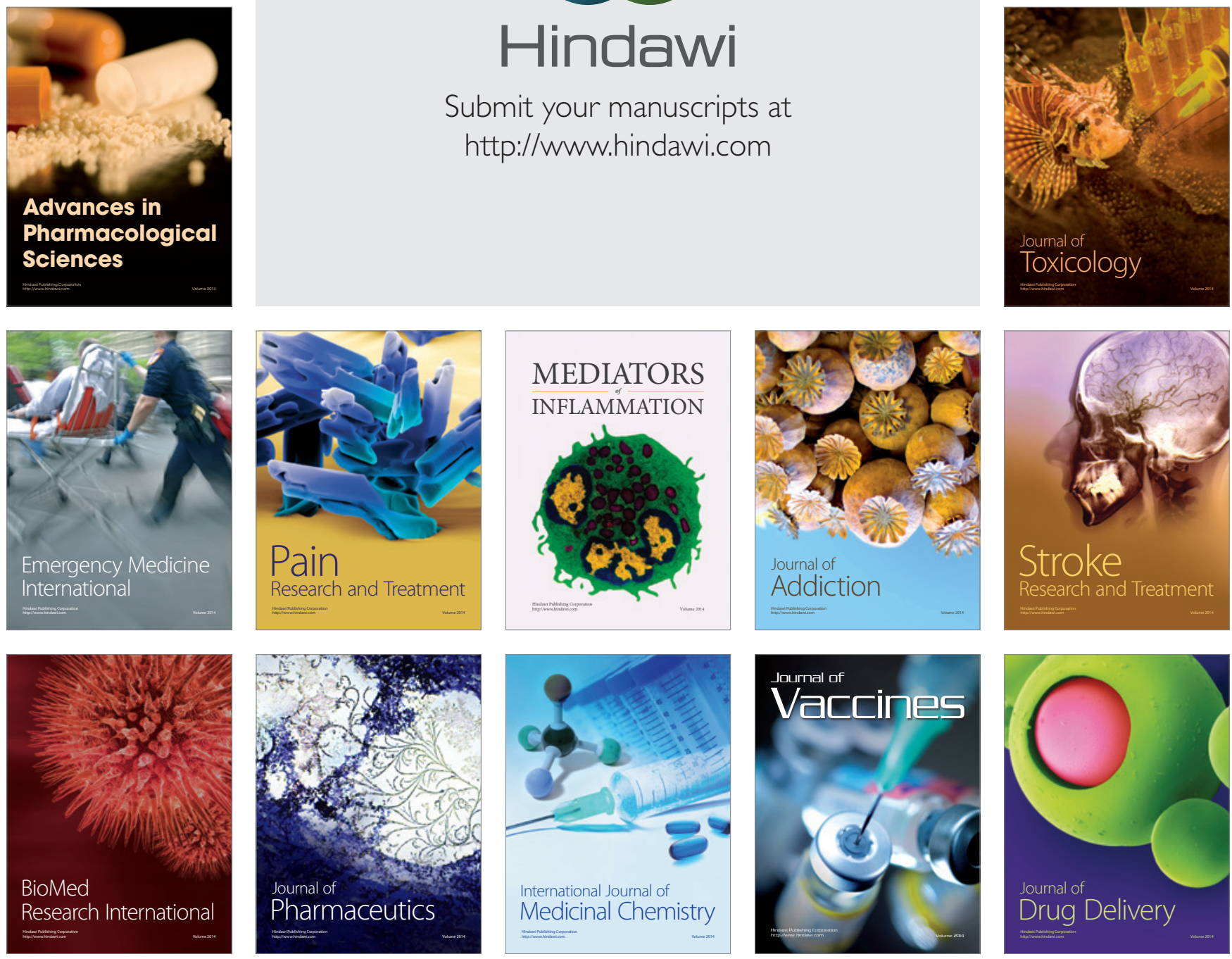